\title{
Rasgos formales de los titulares periodísticos: notas sobre diez diarios del ámbito hispánico
}

\author{
Juan Nadal Palazón
}

Como respuesta a las escasas descripciones existentes sobre los titulares periodísticos - las cuales en algunos aspectos a menudo no superan la prueba empírica que supone cotejarlas con la realidad observable en los periódicos-, en este trabajo se propone un inventario actualizado de las particularidades formales más características de los titulares, de acuerdo con su distribución en un amplio corpus de prensa actual en español. El inventario se resume en cuatro rasgos constantes y cuatro variables. Los rasgos constantes, presentes de manera relativamente homogénea por todo el corpus (si bien algunas de sus variantes presentan ciertos condicionamientos), son los siguientes: bimembración expresiva, elipsis, estructuras nominales y presente histórico. Los rasgos variables, que muestran una distribución menos regular, son, en cambio, los siguientes: tercera persona impersonal, verbo inicial, potencial citativo y presencia de criptónimos.

El análisis se basa en un corpus de 3689 titulares recientes publicados en español en las ediciones impresas de los periódicos El País, de Madrid (España); La Opinión, de Los Ángeles (Estados Unidos); El Universal, de México (México); La Nación, de San José (Costa Rica); Hoy, de Santo Domingo (República Dominicana); El Tiempo, de Bogotá (Colombia); El Nacional, de Caracas (Venezuela); El Comercio, de Lima (Perú); El Mercurio, de Santiago (Chile), y Clarín, de Buenos Aires (Argentina). Cuando procede, se atiende el factor diatópico, y se demuestra la inexactitud de algunos planteamientos que suelen repetirse en la bibliografía especializada.

Palabras Clave: titulares, lengua española, bimembración, elipsis, tercera persona impersonal.

As a reaction to the few existing descriptions of headlines, descriptions which in some respects often fail the empirical proof of comparing them to the observable 
newspapers reality, it is proposed an updated set of the most distinctive formal features of headlines, according to their distribution within a large corpus of current newspapers in Spanish. The set is summarized in four constant and four variable features. The constant features - relatively homogeneous throughout the corpus (although some of its variants have certain conditions) - are: expressive bimembration, ellipsis, nominal structures and historical present. On the other hand, the variable traits — which show a not so regular distribution - are: impersonal third person, verb in starting position, quoting conditional and anthroponyms abbreviated by initializations.

The analysis is based on a corpus of 3689 recent headlines published in Spanish in the printed editions of the following newspapers: El Pais, from Madrid (Spain); La Opinión, from Los Angeles (United States); El Universal, from Mexico City (Mexico); La Nación, from San Jose (Costa Rica); Hoy, from Santo Domingo (Dominican Republic); El Tiempo, from Bogota (Colombia); El Nacional, from Caracas (Venezuela); El Comercio, from Lima (Peru); El Mercurio, from Santiago (Chile), and Clarín, from Buenos Aires (Argentina). Where appropriate, the diatopic factor is considered, and the inaccuracy of some frequent approaches is also demonstrated.

KeYwords: headlines, Spanish, bimembration, ellipsis, impersonal third person.

Fecha de recepción: 7 de noviembre de 2011

Fecha de aceptación: 7 de marzo de 2012 
Juan Nadal Palazón

Instituto de Investigaciones Filológicas

Universidad Nacional Autónoma de México

\section{Rasgos formales de los titulares periodísticos: notas sobre diez diarios del ámbito hispánico ${ }^{1}$}

\section{INTRODUCCIÓN}

Aunque los titulares son, de acuerdo con muchos especialistas, la parte más importante del discurso periodístico impreso (por ejemplo, Van Dijk, Racismo y análisis crítico, 134), constituyen uno de los aspectos del lenguaje informativo que menos atención ha recibido. La escasa producción existente ni siquiera suele superar, de hecho, la prueba empírica que supone confrontar sus planteamientos con la realidad observable en las planas de los periódicos actuales: por lo general, o no encuentran sustento en la producción real cotidiana, o están muy restringidos geográficamente, o ya resultan caducos. ${ }^{2}$

En este trabajo propongo, con carácter exploratorio, un breve inventario actualizado de las particularidades formales más características de este tipo de discurso, que se resume en cuatro rasgos constantes y cuatro variables. Los primeros se hallan de manera relativamente homogénea por todo el corpus, si bien algunas de sus variantes presentan, como

${ }^{1}$ Investigación realizada con el apoyo del Programa de Becas Posdoctorales en la UNAM 2011 (coordinado y administrado por la Coordinación de Humanidades), en el Instituto de Investigaciones Filológicas.

${ }^{2}$ Los pormenores de tal afirmación serán abordados paulatinamente a lo largo de este trabajo. 
veremos, ciertos condicionamientos; los rasgos variables, en cambio, muestran una distribución menos regular.

El análisis se basa en un corpus de 3689 titulares de nota informativa. Esta cifra es el resultado de un muestreo no probabilístico selectivo de cinco cortes temporales para el que se consideraron las notas informativas de todas las secciones de las ediciones impresas de los diarios siguientes: El País, de Madrid (España); La Opinión, de Los Ángeles (Estados Unidos); El Universal, de México (México); La Nación, de San José (Costa Rica); Hoy, de Santo Domingo (República Dominicana); El Tiempo, de Bogotá (Colombia); El Nacional, de Caracas (Venezuela); El Comercio, de Lima (Perú); El Mercurio, de Santiago (Chile), y Clarín, de Buenos Aires (Argentina). Acudo también, muy ocasionalmente, a otras publicaciones. ${ }^{3}$ Los cinco cortes temporales, aleatorios, corresponden a las siguientes semanas: del 5 al 11 de enero de 2009, del 16 al 22 de febrero de 2009, del 18 al 24 de enero de 2010, del 20 al 26 de junio de 2011 y del 24 al 30 de octubre de 2011. Como puede verse, en ningún caso los testimonios son anteriores a 2009, y se ha procurado tener en cuenta publicaciones de las principales ciudades de habla hispana.

Entendido como el "título de una información", el titular es la única "categoría obligatoria dentro del esquema de las noticias" (Vasilachis de Gialdino, La construcción, 35-36). Como bien observa Gomis (Teoría del periodismo, 28), los titulares funcionan con cierta autonomía respecto de los textos que encabezan: debido a que gozan de independencia sintáctica y, hasta cierto punto, semántica, los títulos de las noticias se convierten en textos en sí mismos. Por cuanto integran un conjunto de lectura en cierto modo autónoma e independiente, constituyen, como bien se sabe, las únicas secuencias leídas por gran parte de los consumidores de diarios. Esto es así porque, tal como ha advertido Van Dijk

\footnotetext{
${ }^{3}$ Utilizo las siguientes abreviaturas: ABC, $A b c$ (Madrid, España); CLA, Clarín (Buenos Aires, Argentina); com, El Comercio (Lima, Perú); cro, La Crónica de Hoy (México, México); ELn, El Nacional (Caracas, Venezuela); elp, El País (Madrid, España); HOY, Hoy (Santo Domingo, República Dominicana); Jor, La Jornada (México, México); LAN, La Nación (San José, Costa Rica); MER, El Mercurio (Santiago, Chile); MIL, Milenio Diario (México, México); mun, El Mundo (Madrid, España); oPI, La Opinión (Los Ángeles, Estados Unidos); ReF, Reforma (México, México); тPo, El Tiempo (Bogotá, Colombia); uni, El Universal (México, México).
} 
en su modelo del esquema noticioso (La noticia como discurso, 77-91), el titular suele ser la expresión convencional de macro-proposición de la macroestructura semántica del relato noticioso (es decir, suele ser el resumen del resumen de un texto físicamente contiguo).

Por su codificación lingüística particular, que arroja enunciados separados "con nitidez de las manifestaciones lingüísticas habituales" (Alarcos, "Lenguaje de los titulares", 128-129), los encabezados conforman, de acuerdo con Alarcos "un sistema semiológico particular que aunque derivado de la lengua se superpone a esta" (130). Tal sistema supone, naturalmente, estrategias discursivas específicas que representan respuestas pragmáticas a una serie de factores que concurren en la enunciación: restricciones de espacio, contigüidad con el texto que encabezan, conocimientos previos que se suponen en el lector, periodicidad de la publicación, ideología del medio informativo y del redactor, etcétera.

\section{RASGOS FORMALES CONSTANTES}

\section{Bimembración expresiva}

Debido a que los encabezados son textos producidos en situaciones enunciativas que llevan al límite la tensión entre economía e informatividad, este tipo de discurso ha desarrollado estructuras difícilmente empleadas en otras situaciones de comunicación. Ya Alarcos señalaba la "bimembración expresiva" como un rasgo característico de los titulares periodísticos (146). Según este autor, con dicho recurso el tema y el rema - es decir, la información consabida y la información nueva - se separan "como si dijésemos enfrentándolos" (144), o bien se desgaja por marginación o por relieve alguno de los elementos constitutivos de la secuencia lingüística completa.

\subsection{Bimembración del tipo 1: marco de referencia}

En los ejemplos de la serie (1) se aísla un segmento locativo o tematizador por medio de la escisión marcada gráficamente por los dos puntos. En estructuras de esta clase, producto de lo que denomino bimembra- 
ción del tipo 1, se presenta, marginado y en posición inicial, un encuadre locativo o tematizador: es locativo en los ejemplos (1a) y (1b), y tematizador en (1c) y (1d). La economía lingüística es relativamente escasa en (1a) y (1b), pues solo se prescinde de la modesta preposición en. En (1c) y (1d), por el contrario, se economizan más unidades: estamos ante lo que en la terminología inglesa se conoce como hanging topic - traducido a veces como "tema vinculante"-, procedimiento que tiene por objeto introducir un nuevo tema en el discurso y que suele incorporar locuciones como en cuanto a o con respecto $a$. De acuerdo con la terminología adoptada por Gutiérrez Ordóñez, podemos decir que se trata de "marcos de referencia" o, simplemente, "tópicos" (Temas, remas, 48-58).

(1) a. México: encuentran 5 cadáveres con tiro de gracia [HOY 20/01/10: 16B]

b. HAITÍ: VAN 70 MIL ENTERRADOS [UNI 18/01/10: A1]

c. Aerolíneas: 21 de sus 73 aviones no vuelan por falta de mantenimiento [CLA 19/01/10: 8]

d. Metro: Expertos sugieren construir juntas líneas 6 y 3 [MER 20/01/10: A1]

Registro casos en periódicos de todos los países considerados. En los diarios argentinos y chilenos (particularmente Clarín y El Mercurio) se observa con mayor frecuencia que en los demás. Está presente este tipo de bimembración incluso en las planas de publicaciones cuyos libros de estilo prescriben evitarla, como El País de Madrid: "Los dos puntos se utilizarán [en los titulares] solo cuando después de un nombre propio siga una frase entrecomillada, una frase pronunciada por esa persona" (El País, Libro de estilo, 55). ${ }^{4}$

\subsection{Bimembración del tipo 2: discurso directo}

Algo más abundante, la bimembración del tipo 2 produce el aislamiento del sujeto léxico de un verbum dicendi (o verbo "de decir") elidido. Del otro lado de la marca gráfica, que por lo general es también dos puntos,

${ }^{4} \mathrm{El}$ complejo testimonio (8a), que veremos más adelante, procede de este periódico. 
se ubica la declaración reproducida (es decir, lo que podría llamarse el objeto directo del verbo elidido), ya sea entrecomillada o no. Ausente en otras situaciones de habla, esta partición en dos segmentos se encuentra en todos los periódicos considerados en esta investigación, aunque, eso sí, con órdenes de constituyentes no siempre generalizados. Presentan solamente en posición inicial el sujeto léxico del verbum dicendi los titulares de los periódicos de Argentina, Chile, España, Perú, Venezuela, Costa Rica y República Dominicana, ejemplificados en la serie (2). El orden inverso, representado aquí por la serie (3), se observa en las planas de los periódicos de Colombia, Estados Unidos y México. De acuerdo con mis materiales, alternan ambas pautas únicamente en las planas de los diarios de este último país (Nadal, El discurso ajeno, 44-47).

(2) a. John Travolta: "Tengo el corazón roto" [ELP 06/01/09: 36]

b. Rodrigo Arias: 'Desmentiré ese montón de sandeces' [LAN 21/01/10: 5A]

c. Gubaidulina: «No podemos exigir que toda la gente nos comprenda» [ABC 09/01/09: 43]

(3) a. "Hacer arte no es fumarse un churro": Héctor Falcón [UNI 24/01/10: K20]

b. 'Por ahora, no hay más ayuda en especie': Cruz Roja [тРо 21/01/10: 1-5]

c. Blanco no gana solo: Del Olmo [OPI 19/01/10: 3C]

\subsection{Bimembración del tipo 3: oración atributiva no copulativa}

La bimembración del tipo 3 relaciona, sin verbo copulativo, el sujeto léxico y el atributo. El resultado es, claro está, una oración atributiva no copulativa, ${ }^{5}$ construcción cuya productividad en los titulares ha sido frecuentemente aludida. Por cuanto estas expresiones se forman con grupos nominales que se combinan básicamente con los verbos ser y estar, algunos autores entienden que se trata de elipsis verbales. La

${ }^{5}$ Evidentemente, una discusión sobre el concepto de oración excede los límites metodológicos de este trabajo. 
configuración bimembre destaca diferencialmente los dos componentes de la estructura informativa (tema y rema), por lo general mediante la marca ortográfica de la coma (y su correlativa pausa):

(4) a. Canadá, mercado ideal para orgánicos [Сом 19/01/10: B6]

b. Obama, frustrado por la lentitud de los cambios [тРо 18/01/10: $1-6]$

c. "Ganar dos 'oscars', imposible" [elp 20/01/10: 34]

d. Obsoleto, reglamento de obras en Colima [UNI 22/01/10: A17]

La mayoría de los titulares de este tipo presenta el orden "sujetopredicado", como se observa en los casos (4a)-(4c). Menos frecuente, la pauta inversa ("predicado-sujeto") está ejemplificada por (4d). Esta tendencia a las construcciones absolutas independientes alcanza incluso a segmentos entrecomillados que se exhiben como reproducciones literales, a pesar de que en realidad no lo sean, como en el titular (4c), tal y como demuestra su cotejo con el texto que encabeza.

\section{Elipsis}

Como resultado del principio de economía lingüística, que, como hemos dicho, adquiere en el discurso de los titulares proporciones extremas, los mecanismos de elipsis son, lógicamente, soluciones habituales en la codificación de los encabezados. Identifico cuatro tipos de elipsis habituales en este tipo de enunciados.

Antes de hablar de cada una de ellas, conviene advertir, sin embargo, que no son pocos los autores que censuran esta tendencia a elidir segmentos lingüísticos. Se la ha tildado de "antiestético laconismo", de "esquematismo inhumano, sin gracia y sin belleza" y hasta de "vicio norteamericano" (Martín Vivaldi, Géneros periodísticos, 219 y 234; Curso, 376). No son inhabituales, de hecho, las críticas que en unos países se hacen sobre las particularidades morfosintácticas de los titulares de la prensa de otros países, y se opina negativamente atribuyendo a ciertos usos, como algunas elipsis, orígenes estadounidenses como consecuencia de un "subdesarrollo periodístico" y un "imperialismo socio- 
cultural" (Gómez Mompart, Los titulares en prensa, 59; Fontcuberta, La noticia, 121; López Hidalgo, El titular, 63).

No obstante las numerosas críticas — que apuntan normalmente a cuestiones de incorrección o incomprensión-, y aun las claras proscripciones en libros de estilo (Abc, Libro de estilo, 165; El País, Libro de estilo, 51; El Universal, Guía de estilo, 32), los distintos tipos de elipsis que mencionaré en seguida son muy vitales en las planas de los diarios en español. Es evidente que, si de verdad fueran imposibles de decodificar, difícilmente seguirían en uso. Con frecuencia llamados peyorativamente "telegráficos", los titulares elípticos son comprensibles, dice el propio Gómez Mompart, "de igual modo que todo el mundo entiende un telegrama" (Los titulares en prensa, 110).

\subsection{Elipsis del tipo 1: verba dicendi}

A la supresión de verbos que acompaña a la bimembración expresiva del tipo 2 (verbos de decir en discurso directo) - que denomino arbitrariamente elipsis del tipo 1 -, se suman otras tres formas de elipsis que, por su insistente presencia en los titulares, se convierten asimismo en un rasgo de este tipo de discurso: las elipsis de artículos, de nexos y de sustantivos. Retomo aquí nuevamente algunos ejemplos de elipsis de verbum dicendi en discurso directo (bimembración del tipo 2):

(5) a. Rodrigo Arias: 'Desmentiré ese montón de sandeces' [LAN 21/01/10: 5A]

b. "Hacer arte no es fumarse un churro": Héctor Falcón [UNI 24/01/10: K20]

\subsection{Elipsis del tipo 2: determinantes}

Llamo elipsis del tipo 2 a la supresión de determinantes. Las características tan específicas de la situación de textualización de los encabezados favorece, como se sabe, la omisión de artículos, posesivos y demostrativos, por lo que no es infrecuente el uso de grupos nominales escuetos en los títulos de las noticias. Parece que esta elección morfostntáctica se 
ha convertido en índice de situación para los titulares, hasta el punto de presentarse, a veces, incluso con sustantivos contables en singular.

(6) a. Hampones golpean a esposa de médico amenazado [LAN 20/01/10: 12A]

b. La Paz deja entrever inquietud por futuro de agenda de diálogo que incluye tema marítimo [MER 19/01/10: C2]

c. Dan de alta a niño herido por pedrada [Сом 20/01/10: A10]

d. Muere fundador de Taco Bell [UNI 19/01/10: B7]

e. Austríaco busca romper barrera del sonido con su cuerpo [Hоу 23/01/10: 9B]

Las Academias entienden que, en este registro escrito, la ausencia de artículos "se interpreta como marca de inespecificidad" (Real Academia Española y Asociación de Academias de la Lengua Española, Nueva gramática, §15.12f). Es necesario aclarar, empero, que no siempre resulta pertinente esta interpretación, como a todas luces ocurre, por ejemplo, con esposa, futuro y barrera del sonido en los testimonios (6a), (6b) y (6e), respectivamente (solamente hay una barrera del sonido, por ejemplo).

Fuera de Hispanoamérica suele decirse que las elisiones de determinantes constituyen un fenómeno exclusivo de los titulares del "periodismo americano" (Alarcos, "Lenguaje de los titulares", 146; Real Academia Española y Asociación de Academias de la Lengua Española, Nueva gramática, §15.12g). Es habitual leer descripciones que presentan este fenómeno como un rasgo que distingue a los periódicos hispanoamericanos frente a los españoles, pues, según se acostumbra decir, los determinantes - y en particular los artículos - están "siempre presentes en la prensa española y solo en algunos casos en la prensa hispanoamericana” (Gómez Sánchez, “¿Cómo lo cuentan allá?”, 54; las cursivas son mías).

Los materiales de mi corpus, sin embargo, indican que, si bien es cierto que la elipsis del tipo 2 es más abundante en las planas de algunos diarios hispanoamericanos que en los españoles, en realidad en España es hoy en día un procedimiento habitual, pero - eso sí- de productividad más restringida y condicionada. Mientras que en los en- 
cabezados de buena parte de Hispanoamérica — ejemplificados en la serie (6) - los determinantes se omiten en cualquier contexto (pero más en posición inicial), en España este fenómeno tiene lugar, de acuerdo con mis materiales, sobre todo ante sustantivos colectivos o nombres de instituciones, y particularmente si se hallan en función de núcleo del sujeto cuando este argumento se sitúa en posición preverbal, como se comprueba con la serie (7), integrada totalmente por ejemplos de la prensa española:

(7) a. Militares recuerdan a Chacón que ellos pueden ser arrestados por vestir de forma inadecuada [MUN 08/01/09: 12]

b. Comandos israelíes juntan a los varones, los atan y desnudan [MUN 06/01/09: 21]

c. PP y PSOE buscan la fórmula para ampliar a toda la vida laboral el cálculo de la pensión [ABC 05/01/09: 28]

d. PNV, PSE y 'abertzales' tachan de político el juicio a Ibarretxe y López [ELP 08/01/09: 12]

e. Los empleados de Lloyds aceptan reducir plantilla un $30 \%$ [ELP 19/01/10: 22]

Queda demostrada, pues, la inexactitud del supuesto "empleo completo" (Rebollo Torío, "Análisis de titulares", 165) de determinantes en los titulares de la prensa española. Más o menos frecuente según el país y el diario, la elipsis de determinantes es, en realidad, un rasgo característico de los titulares periodísticos en todo el ámbito hispánico. Cabe precisar que, si hay un lugar donde es relativamente poco habitual este tipo de elipsis, es Argentina. De hecho, no recojo casos indiscutibles del periódico bonaerense Clarín, pero no por ello puede decirse que el fenómeno no se presente en ese país sudamericano, a juzgar por los ejemplos que se observan en el corpus de encabezados argentinos recopilado por Guntern Weibel ("Los titulares hablan", 1951-1960).

\subsection{Elipsis del tipo 3: nexos}

Muy frecuente en los diarios del mundo hispánico es la omisión de nexos, a la que nos referiremos en lo sucesivo como elipsis del tipo 3. No se tra- 
ta, desde luego, de un fenómeno exclusivo de los titulares ni del registro periodístico de la lengua, pero, en opinión de Casado Velarde, probablemente se ha extendido desde este ámbito a otras esferas de la lengua ("La supresión de nexos", 224). En los encabezados adquiere, en todo caso, proporciones mayores.

(8) a. Penélope Cruz / Kate Winslet: diamantes, fuera [ELP 18/02/09: 37]

b. PRI-PVEM van por un distrito [UNI 08/01/09: A13]

En la serie (8) reproduzco ejemplos de un primer grupo: en estos casos se omite una conjunción. La relación de enlace se marca por medio de algún índice gráfico - ya guión (-), ya barra (/) — que enfrenta dos elementos nominales. En ambos ejemplos, estos signos ortográficos auxiliares sustituyen a la conjunción copulativa $y$. Puesto que, si es posible hablar de economía lingüística, esta resulta mínima, no parece excesivamente aventurado suponer que tales construcciones encuentran su motivación en una tendencia a establecer relaciones de contraposición mediante signos ortográficos sin correlato articulatorio. De hecho, puede decirse que, en casos como (8a), el primer segmento que resulta de una bimembración del tipo 1 está también expresivamente bimembrado: ambos nombres aparecen enfrentados por medio de una barra. En los dos titulares de la serie se establece una relación paratáctica entre los elementos contrapuestos por medio del guión o la barra (relación claramente evidenciada en el segundo ejemplo por la concordancia del verbo). En (8b) se presentan, asimismo, casos de elipsis del tipo 2.

Identifico un segundo grupo de elipsis del tipo 3: aquí dos o más elementos enfrentados mediante guiones funcionan como el complemento de un sustantivo, sin la intermediación de los nexos prepositivos que estarían presentes en otras situaciones enunciativas. En los casos que ahora nos ocupan, se conserva la relación hipotáctica a pesar de la ausencia de un nexo prepositivo. El resultado es una construcción apositiva especificativa, esquema cuya productividad ya identificó Lapesa, donde "todo se concita para que el sustantivo, sin adición de sufijos y sin transpositor, asuma con frecuencia funciones de adjetivo" ("Tendencias y problemas actuales", 222). Reproduzco algunos ejemplos en la serie (9): 
(9) a. Prevén diálogo Obama-Hamas [REF 9/01/09: INT 1]

b. Aguda tensión Chávez-Uribe [OPI 18/01/10: 11A]

c. Valcárcel advierte que se rebelará si se cercena el trasvase Tajo-Segura [ELP 20/01/10: 14]

d. Alianza PT-PRD-PAN, "un engendro maligno": PRI [UNI 23/01/10: A16]

Martínez de Sousa habla en estos casos de guión prepositivo porque considera que por lo general tal signo sustituye a una preposición y "raramente a una conjunción" (Ortografía y ortotipografia, 436). En todos los ejemplos de la serie, sin embargo, parece que, al igual que en el grupo anterior, este signo sustituye a una conjunción copulativa (diálogo Obama-Hamas < diálogo entre Obama y Hamas). Si bien la dualidad es el patrón dominante - expresada a menudo por los sustantivos subordinantes: diálogo, tensión, trasvase - , en ocasiones se ponen en relación más de dos términos, como sucede en el testimonio (9d).

El último grupo de elipsis del tipo 3 corresponde a los casos de omisión de preposiciones y conjunciones sin la presencia de signos ortográficos auxiliares. Es la que más críticas ha suscitado y, acaso por ello, la menos usual. De todos los periódicos considerados en esta investigación, el dominicano Hoy es el que presenta estas elipsis de modo más generalizado:

(10) a. Foro sugiere pacto superar el deficiente servicio electricidad [ноу 20/01/10: 12A]

b. Estrella acusa autoridades complicidad narco [ноу 18/01/10: $10 \mathrm{~A}]$

c. Presidente Senado Haití herido sismo estable tras cirugía [HOY 18/01/10: 4A]

d. Dice espera aprobación ley partidos [HOY 26/01/10: 5A]

Los enunciados anteriores podrían parafrasearse así: (Cierto) foro sugiere (un) pacto PARA superar el deficiente servicio DE electricidad; (Una) estrella acusa A (las) autoridades DE complicidad CON (el) narco; (El) presidente DE (l) Senado DE Haití, herido EN (el) sismo, estable tras (una) cirugía; Dice QUE espera (la) aprobación DE (la) ley DE par- 
tidos. Este tipo de formulaciones no parecen ser más que respuestas a la necesidad de condensar la información en un espacio muy limitado, pero llevadas a casos límite. En cuanto a las elipsis de preposiciones, es probable que en algunos casos se vean favorecidas por las actitudes de repudio, frecuentes en el gremio periodístico, hacia este tipo de nexos cuando se sitúan al final de un renglón en los encabezados.

\subsection{Elipsis del tipo 4: sustantivos}

La economía lingüística de los encabezados llega incluso a la omisión del sustantivo subordinante - elipsis del tipo 4-, como se advierte en los ejemplos de (11). De ningún modo exclusivo de los titulares, pero sí muy frecuente en ellos, este procedimiento obliga al lector a restituir, mediante un proceso inferencial, el núcleo de un sintagma nominal. En los titulares (11a), (11b) y (11e), se han suprimido los sustantivos centrales, Tribunal y conflicto, respectivamente. En (11c) y (11d), se trata de elecciones. En (11e) se advierte además una elipsis del tipo 2 y bimembraciones de los tipos 1 y 3 .

(11) a. Las nucleares salvan a Francia [ABC 08/01/09: 23]

b. El Supremo de EE UU permite financiar sin límite las campañas [ELP 22/01/10: 11]

c. Rajoy nombra a Mayor Oreja candidato a las europeas tras el ascenso en los sondeos de Díez [MUN 05/01/09: 7]

d. ELN Mesa de la Unidad designó comisión para las primarias [ELN 19/01/10: A2]

e. Televisa-Univisión: en un mes, la decisión del juez [MIL 08/01/09: 20]

Estas omisiones también son repudiadas con cierta frecuencia (La Vanguardia, Libro de redacción, 15, por ejemplo). Tal opinión, claro está, no es unánime en el gremio periodístico. Grijelmo, quien fue redactor del periódico madrileño El País durante años, de hecho recomienda a los periodistas neófitos acudir a este procedimiento para disminuir la extensión de los encabezados: "Se puede tomar una palabra del grupo y usarla con valor equivalente al total" (El estilo del periodista, 489). Y añade 
una anécdota: "Cuando en España se empezó a escribir 'el Constitucional' muchos lectores criticaban una expresión tan extraña, y ahora ya se ha acostumbrado todo el mundo" (El estilo del periodista, 489).

\section{Estructuras nominales}

Aunque a veces los periodistas consideran impropios los titulares sin verbo, en realidad los encabezados unimembres, y en particular los que están constituidos por un sintagma nominal, son bastante "frecuentes en la prensa de cualquier país hispanohablante" (Romero Gualda, "Rasgos morfosintácticos", 547). Las secuencias de este tipo, ejemplificadas en la serie (12), representan la más clara expresión del valor de rótulo que tienen los encabezados, pues se convierten en un nombre identificador del contenido de la noticia.

(12) a. Derrame de petróleo en Texas [LAN 24/01/10: 26A]

b. Alerta epidemiológica por dengue [ELN 22/01/10: C9]

c. Sismo de 4,1 grados [сом 18/01/10: A17]

d. Demanda contra intendenta por daños [MER 21/01/10: C8]

En los titulares, el principio de economía lingüística, aunado a otras motivaciones, ocasiona que muchos procesos, normalmente expresados con verbos, se reformulen como sustantivos, con lo que suele perderse información argumental, circunstancial, temporal, modal y aspectual (Nadal, "Verdades a medias", 175-189). Así, mediante el uso de nominalizaciones deverbales, las unidades que en la oración completa hubieran cumplido funciones argumentales - es decir, adyacentes del verbo - pasan a ser determinantes del sustantivo y, por consiguiente, fácilmente eliminables.

\section{Presente histórico}

La inmensa mayoría de titulares con verbo explícito se formula en presente de indicativo, a pesar de que normalmente los acontecimientos 
noticiosos son sucesos pasados. Esta práctica es hoy, asegura Bastenier, un recurso habitual "en toda la prensa occidental" (El blanco móvil, 57). Transcribo algunos ejemplos hispánicos en la serie (13).

(13) a. Granjero mata a 51 vacas y se suicida [Coм 24/01/10: B3]

b. Liberan a colombiano en Nigeria [тРо 19/01/10: 1-7]

c. Autoriza juez subasta de vestido de Spears para Haití [UNI 24/01/10: K4]

d. Cristina anuncia la creación del Fondo [CLA 24/01/10: 6]

e. Un hombre mata a ocho personas en Virginia [eLP 21/01/10:3]

f. Bolivianos armados cruzan la frontera y asaltan a empresa [MER 24/01/10: C16]

Los tratadistas del periodismo suelen argüir que, de esta manera, los encabezados dan la idea de que los acontecimientos acaban de ocurrir o bien que no han terminado de pasar. La expresión de sucesos o estados pasados por medio del presente de indicativo - conocida como presente histórico - es estudiada en casi todos los manuales de gramática y suele explicarse o presentarse implícitamente como una neutralización en el sistema de oposiciones estructurales que contiene el sistema verbal español o como una transposición o dislocación temporal que actualiza hechos pretéritos.

El presente histórico comporta efectos estilísticos de proximidad, viveza y fuerza dramática. Debido a ello se emplea en la narrativa oral para referir momentos climáticos de la historia relatada, tal como ha observado Silva-Corvalán. De acuerdo con ella, el presente de indicativo se utiliza en las cláusulas narrativas de los relatos orales como elemento evaluativo, es decir, como recurso mediante el cual "el narrador hace que la historia parezca interesante, divertida, entretenida o fuera de lo usual" (Sociolingüistica y pragmática, 204). En cuanto relatos condensados o extractados, los titulares — poseedores, según se ha demostrado, de un componente fundamental de carácter oral (Guntern Weibel, "Los titulares hablan", 1951-1960) — parecen compartir este uso evaluativo del presente histórico: recuérdese que, con ellos, el periodismo busca impresionarnos y persuadirnos de que suceden cosas interesantes. En este tipo de situaciones, el presente histórico se utiliza 
para indicar la relevancia de una cláusula narrativa llamando la atención sobre ella por medio de un efecto retórico de proximidad: "Al usar el Presente de Indicativo para describir hechos ocurridos en el pasado, el hablante los presenta como si los estuviera viendo en el momento de hablar", dice Silva-Corvalán (Sociolingüistica y pragmática, 204-205), y añade que la narrativa se torna así "más vívida y dramática" (205). Lo mismo sucede con los encabezados, que ya son, per se, evaluaciones del contenido de las noticias.

\section{RASGOS FORMALES VARIABLES}

\section{Tercera persona impersonal}

Los periódicos hispanoamericanos presentan una indudable tendencia al uso de construcciones de interpretación impersonal en tercera persona del plural. El fenómeno es mucho menos frecuente en la prensa española, pero no imposible de rastrear. Hay que insistir en que, en los diarios de Hispanoamérica, prácticamente no hay edición que no contenga una buena cantidad de ejemplos, ya sea que se conozca o no el agente del proceso.

(14) a. Informan sobre la reforma migratoria [OPI 22/01/10:3A]

b. Recuperan Planta Centro con lentitud [ELN 24/01/10: A1]

c. Instalan diálogo para ayudar a economía [LAN 20/01/10: 24A]

d. Frenan ayuda no alimentaria [тРо 20/01/10: 1-6]

(15) Asesinan a tiros a un capo colombiano de la droga en el Doce de Octubre [ABC 09/01/09: 20]

En las oraciones de este tipo -no exclusivas de los encabezados, naturalmente - la tercera persona del plural adquiere un significado indefinido o indeterminado cuando alude bien sea a un sujeto sobreentendido o desconocido, como en (15), o bien a un sujeto cuya referencia no interesa expresar, como en los casos de (14). Los testimonios 
como (15), normalmente referidos a cuestiones policíacas o judiciales, se encuentran tanto en los periódicos hispanoamericanos como en los españoles. En cambio, los de la serie (14), de referencias mucho más amplias y no siempre fáciles de determinar sin leer el texto contiguo, son casi exclusivos de Hispanoamérica.

\section{Verbo inicial}

Es relativamente frecuente que, en los diarios hispanoamericanos, los titulares con verbo expreso presenten esta palabra en posición inicial. Como bien observaba Lapesa con respecto a los encabezados de prensa hispanoamericana, "mediante alteraciones en el orden normal de las palabras se intenta destacar los términos de mayor interés y orientar la atención de los lectores" ("La lengua", 200). Si consideramos que, para los periodistas, el título "debe ser trabajado en forma que contenga en las primeras palabras lo esencial de la noticia" (Sociedad Interamericana de Prensa, Manual de estilo, 86) y que, como también suele decirse en el gremio, "la noticia es actividad, y el verbo representa acción" (Abc, Libro de estilo, 165), no resulta extraña la presencia de estructuras hiperbáticas como las de (16) en las planas de muchos diarios.

(16) a. Desafía Cuevas a Ebrard [MIL 09/01/09: 1]

b. Estudia la UCLA violaciones a derechos laborales en LA [OPI 19/01/10: 8A]

c. Es Iztapalapa delegación que más ensucia sus calles [UNI 09/01/09: C1]

d. Muere hombre de dos puñaladas tras riña [LAN 22/01/10: 12A]

En opinión de Hurtado, con este orden de constituyentes "el titular adquiere un mayor dinamismo y expresividad" (El uso del lenguaje, 35). Además de esta posible motivación estilística y de la pretensión de destacar la referencia a un proceso verbal, este orden propicia la tendencia hispanoamericana a formular encabezados en oraciones impersonales en tercera persona del plural, como sucede en los ejemplos de (14), que ya hemos visto. 
Según datos de Steel, este fenómeno oscila entre el $8 \%$ y el $20 \%$ en los titulares de periódicos de Argentina, Colombia, Chile, México, Paraguay, Perú y Venezuela ("Los estilos funcionales", 184). De acuerdo con Dubský y Heredia ("Los titulares discursivos", 33), la frecuencia asciende al $82 \%$ en la prensa cubana. Según mis materiales, si excluimos los casos de construcciones impersonales en tercera persona del plural, así como los de sujeto tácito o extenso, el universo se restringe a los diarios de América del Norte, América Central y el Caribe insular. Como afirma Romero Gualda, "no se trata de un rasgo que no pueda rastrearse en la prensa española, pero en mucha menor proporción" (“Rasgos morfosintácticos”, 544).

\section{Potencial citativo}

Relativamente usual en los titulares es el empleo del potencial citativo, es decir, las formas de condicional simple o compuesto (pospretérito o antepospretérito) empleadas para "dar a entender que se trata de aseveraciones ajenas, suposiciones cuya veracidad no se asegura o rumores no confirmados" (Lapesa, "Tendencias y problemas actuales", 88). A menudo censurado por su origen francés, este uso periodístico del condicional se observa en toda la prensa del ámbito hispánico, a excepción de los periódicos estadounidenses editados en lengua española.

(17) а. Venezuela doblaría en reservas a A. Saudí [тРо 24/01/10: $1-6]$

b. Sería Ovelar [REF 11/01/09: CAN 8]

c. Sector construcción habría crecido 5,2\% [сом 19/01/10: B4]

\section{Criptónimos}

Un rasgo característico de la prensa mexicana es la abreviación de antropónimos por medio de siglas. Parece que, en general, los periódicos de México tienden más que los demás al uso de abreviaturas en los titulares. Ya observó Manuel Seco que es poco corriente en España la 
costumbre de referirse a una persona por medio de las iniciales de su nombre ("El léxico de hoy", 193), pero Martínez de Sousa afirma que "en el lenguaje periodístico sí se han utilizado a veces los criptónimos" (Diccionario de ortografía, 156). En mi corpus no registro ejemplos en titulares españoles ni de ningún otro país distinto de México. No es, por tanto, "una tendencia muy extendida", como asegura Rivadeneira Prada (Periodismo, 169). Puedo decir que se trata de un recurso que la prensa mexicana emplea casi sistemáticamente para aludir a personajes muy conocidos, como el presidente de la República. En (18), los criptónimos $F C H, A M L O$ y $V F Q$ aluden a Felipe Calderón Hinojosa, Andrés Manuel López Obrador y Vicente Fox Quesada, respectivamente.

(18) a. FCH urge a ubicar mexicanos en Haití [UNI 23/01/10: A8]

b. Delinea AMLO plan emergente para atender a 7 millones de ninis [JOR 25/10/11: 1]

c. Pide senadora a VFQ callar y contribuir a la unidad panista [CRO 21/06/11: 4]

\section{CONCLUSIONES}

Primera. En esta exploración, he identificado cuatro rasgos constantes y cuatro variables. Puede decirse que los titulares periodísticos presentan una fuerte tendencia a configuraciones elípticas y expresivamente bimembradas, así como a estructuras de tipo nominal y al uso del presente histórico. Aunque de manera ocasional, se observan también casos de potencial citativo en toda la prensa hispánica. Los titulares hispanoamericanos, a diferencia de los españoles, tienden a ser estructurados en oraciones impersonales en tercera persona del plural y, en menor medida, a presentar fórmulas con el verbo en posición inicial. Un rasgo característico de la prensa mexicana es el uso recurrente de criptónimos en sus encabezados.

Segunda. Salvo el presente histórico y el verbo en posición inicial, todos estos rasgos responden, al menos parcialmente, al principio general de economía lingüística, que en los titulares encuentra una de sus expresiones más evidentes. El hecho de que los titulares españoles y 
argentinos tiendan a ser ligeramente más extensos que los demás parece explicarse por la menor frecuencia de uso de la elipsis del tipo 2 en la prensa de esos países.

Tercera. En algunos casos, como los de las oraciones impersonales en tercera persona del plural y de las nominalizaciones deverbales -íntimamente relacionadas con la abundancia de titulares unimembres-, la economía lingüística puede acompañarse de motivaciones de otro tipo. Considerando que los periodistas saben que los titulares son las únicas secuencias leídas por la mayoría de los consumidores de diarios, la elección de fórmulas que comportan la pérdida de información importante, como el sujeto léxico, podría revelar la existencia de estrategias persuasivas. Recuérdese que, de acuerdo con el modelo del cuadrado ideológico de Van Dijk, las omisiones a menudo suponen rivalidades y ponen en evidencia posturas ideológicas.

Cuarta. La bimembración, en principio acompañada de elipsis verbal, es un recurso expresivo tan característico del discurso de los titulares que se presenta también en las oraciones con verbo explícito. Me refiero a los casos de bimembración del tipo 1 con función de encuadre locativo, donde la economía lingüística es mínima. La existencia del primer grupo de elipsis del tipo 3 (conjunciones copulativas) también apunta a una tendencia a marcar relaciones de contraposición por medio de signos ortográficos sin correlato articulatorio.

Quinta. El presente histórico y el verbo en posición inicial son rasgos básicamente estilísticos y, por ende, la apreciación de sus efectos es en buena medida subjetiva. Lo que Alarcos llama una "ordenación anormal de las unidades sintácticas" (Alarcos, "Lenguaje de los titulares", 146) pretende destacar lo que el periodista considera de mayor interés, para presuntamente orientar la atención de los lectores e imprimir al encabezado "mayor dinamismo y expresividad" (Hurtado, El uso del lenguaje, 35). En la prensa hispanoamericana, también propicia este orden la tendencia a formular los encabezados en oraciones impersonales en tercera persona del plural. En cuanto al presente histórico, de uso generalizado en los diarios de ambos países, suele decirse que comporta efectos de proximidad, viveza y fuerza dramática. 


\section{REFERENCIAS}

ABC, Libro de estilo de ABC, Barcelona, Ariel/Abc, 2a ed., 2001 (Ariel Lingüística).

Alarcos Llorach, Emilio, "Lenguaje de los titulares", en Lenguaje en periodismo escrito, Fernando Lázaro Carreter (ed.), Madrid, Fundación Juan March, 1977 (Serie Universitaria, 37), 125-148.

Bastenier, Miguel Ángel, El blanco móvil. Curso de periodismo, México, Aguilar/Ediciones El País, 2001.

Casado Velarde, Manuel, "La supresión de nexos en los titulares de prensa: el tipo 'las relaciones Londres-Dublín'”, Archivum, 38, 1986, 223-228.

Dubský, Josef y Thelvia Heredia Vedey, "Los titulares discursivos en la prensa cubana", Ibero-Americana Pragensia, 11, 1977, 31-38.

El PAís, Libro de estilo, Madrid, Ediciones El País, 18a ed., 2003.

El Universal, Guía de estilo, México, El Universal, 2004.

Fontcuberta, Mar, La noticia. Pistas para percibir el mundo, Barcelona, Paidós, 1993 (Papeles de Comunicación, 1).

Gómez Mompart, José Luis, Los titulares en prensa, Barcelona, Mitre, 1982.

Gómez SÁnchez, María Elena, “Cómo lo cuentan allá? Análisis de un conjunto de titulares de la prensa española y americana", Español Actual, 89, 2008, 39-55.

Gomis, Lorenzo, Teoría del periodismo: cómo se forma el presente, México, Paidós Mexicana, 1991 (Paidós Comunicación, 44).

Grijelmo, Álex, El estilo del periodista, México, Taurus, 2003 (Pensamiento). Guntern WeiBel, Elba, "Los titulares hablan", en Lengua, discurso, texto (I Simposio Internacional de Análisis del Discurso), vol. II, Patrick Charaudeau, Joesé Luis Girón Alconchel et al. (eds.), Madrid, Visor Libros, 2000, 1951-1960.

GutiérRez OrdóÑEz, Salvador, Temas, remas, focos, tópicos y comentarios, Madrid, Arco Libros, 2a ed., 2000 (Cuadernos de Lengua Española, 46).

Hurtado GonzÁlez, Silvia, El uso del lenguaje en la prensa escrita, Valladolid, Universidad de Valladolid, 2003 (Lingüística y Filología, 56).

La VAnguardia, Libro de redacción de "La Vanguardia”, Barcelona, La Vanguardia/TISA, 1986.

LAPESA, Rafael, "La lengua desde hace cuarenta años", Revista de Occidente, 8-9, 1963, 193-208.

LAPESA, Rafael, "Tendencias y problemas actuales de la lengua española”, en Comunicación y lenguaje, Rafael Lapesa (ed.), Madrid, Karpós, 1977, 207-229.

López Hidalgo, Antonio, El titular: manual de titulación periodística, México, Alfaomega, 2009. 
Martín Vivaldi, Gonzalo, Curso de redacción. Teoría y práctica de la composición y del estilo, Madrid, Paraninfo, 33a ed. actualizada por Arsenio Sánchez Pérez, 2000.

Martín Vivaldi, Gonzalo, Géneros periodísticos, Madrid, Paraninfo, 6a ed., 1998.

Martínez de Sousa, José, Diccionario de ortografía, Madrid, Ediciones Generales Anaya, 1985.

Martínez de Sousa, José, Ortografía y ortotipografía del español actual, Gijón, Trea, 2004 (Biblioteconomía y Administración Cultural, 95).

Nadal Palazón, Juan, El discurso ajeno en los titulares de la prensa mexicana, México, Universidad Nacional Autónoma de México, 2009 (Posgrado, 37).

NADAl PALAzÓn, Juan, "Verdades a medias: la nominalización deverbal en los titulares periodísticos”, Comunicación y Sociedad, 9 (nueva época), 2008, 175-189.

Real Academia Española y Asociación de Academias de la Lengua Española, Nueva gramática de la lengua española, vols. I y II, Madrid, Espasa Libros, 2009.

Rebollo Torío, Miguel Á., "Análisis de titulares en la prensa hispana”, Anuario de Estudios Filológicos, 31, 2008, 163-175.

Rivadeneira Prada, Raúl, Periodismo: la teoría general de los sistemas y la ciencia de la comunicación, México, Trillas, 5a ed., 2007.

Romero Gualda, María Victoria, "Rasgos morfosintácticos de la prensa americana", en El español de América. Actas del III Congreso Internacional de El Español de América, vol. I, Germán de Granda, Carmen Hoyos et al. (eds.), Salamanca, Junta de Castilla y León, 1991, 541-549.

Seco, Manuel, "El léxico de hoy”, en Comunicación y lenguaje, Rafael Lapesa (ed.), Madrid, Karpós, 1977, 183-201.

Silva-CoRvalán, Carmen, Sociolingüística y pragmática del español, Washington, Georgetown University Press, 2001.

Sociedad Interamericana de Prensa, Manual de estilo, Nueva York, Hobbs, Dorman \& Company, 1965.

SteEl, Brian, "Los estilos funcionales y la enseñanza del idioma", Español Actual, 18, 1971, 9-18.

VAn DiJK, Teun A., La noticia como discurso [1980], trad. Guillermo Gal, Barcelona, Paidós, 1990 (Paidós Comunicación, 41).

VAn Disk, Teun A., Racismo y análisis crítico de los medios, trad. Montserrat Basté Kraan, Barcelona, Paidós, 1997 (Paidós Comunicación, 82).

VASIlACHIS DE GiALdino, Irene, La construcción de las representaciones sociales. Discurso político y prensa escrita. Un análisis sociológico, jurídico y lingüístico, Barcelona, Gedisa, 1998 (Hombre y Sociedad, ClA-DE-MA). 